\title{
A Diabetes Pay-for-Performance Program and Risks of Cancer Incidence and Death in Patients With Type 2 Diabetes in Taiwan
}

\author{
Hui-Min Hsieh, $\mathrm{PhD}^{1,2}$; Jiun-Shiuan $\mathrm{He}, \mathrm{MS}^{3}$; Shyi-Jang Shin, $\mathrm{MD}, \mathrm{PhD}^{4,5}$; \\ Herng-Chia Chiu, $\mathrm{PhD}^{6,7}$; Charles Tzu-Chi Lee, $\mathrm{PhD}^{8}$
}

\begin{abstract}
Accessible Version: www.cdc.gov/pcd/issues/2017/17_0012.htm
Suggested citation for this article: Hsieh HM, He JS, Shin SJ, Chiu HC, Lee CT. A Diabetes Pay-for-Performance Program and Risks of Cancer Incidence and Death in Patients With Type 2 Diabetes in Taiwan. Prev Chronic Dis 2017;14:170012. DOI: https://doi.org/10.5888/pcd14.170012.
\end{abstract}

\section{PEER REVIEWED}

\section{Abstract}

\section{Introduction}

We sought to evaluate the effects of diabetes disease management through a diabetes pay-for-performance (P4P) program in Taiwan on risks of incident cancer and mortality among patients with type 2 diabetes.

\section{Methods}

We conducted a longitudinal observational cohort study using 3 population-based databases in Taiwan. Using propensity score matching, we compared patients with type 2 diabetes who enrolled in a P4P program with a similar group of patients who did not enroll in the in P4P program (non-P4P). Primary end points of interest were risks of incident cancer and all-cause, cancer-specific, and diabetes-related mortality. Total person-years and incidence and mortality rates per 1,000 person-years were calculated. Multivariable Cox proportional hazard models and competing risk regression were used in the analysis.

\section{Results}

Overall, our findings indicated that the diabetes P4P program was not significantly associated with lower risks of cancer incidence, but it was associated with lower risks of all-cause mortality (adjusted subdistribution hazard ratio [aSHR], $0.59 ; 95 \%$ confidence interval $[\mathrm{CI}], 0.55-0.63$ ), cancer-specific mortality (aSHR, 0.85;
95\% CI, 0.73-1.00), and diabetes-related mortality (aSHR, 0.54: 95\% CI, 0.49-0.60). Metformin, thiazolidinediones, and $\alpha$ glucosidase inhibitors were associated with lower risks of cancer incidence and cancer-specific mortality.

\section{Conclusion}

Our findings provide evidence of the potential benefit of diabetes $\mathrm{P} 4 \mathrm{P}$ programs in reducing risks of all-cause mortality and competing causes of death attributable to cancer-specific and diabetes-related mortality among type 2 diabetes patients.

\section{Introduction}

Diabetes mellitus and cancer are common, serious global health problems that contribute substantially to health care costs. A 2014 report from the International Diabetes Federation estimated that more than 387 million people worldwide have diabetes, and by 2035 this number will rise to 592 million; 4.9 million deaths and at least US $\$ 612$ billion in health expenditure resulted from diabetes in 2014 (1). Diabetes is considered a strong independent predictor of vascular diseases (2). Growing evidence suggests a possible association between diabetes (especially type 2 diabetes) and sitespecific cancer risks (eg, liver, breast, colorectal), as well as cancer mortality $(3,4)$.

Although the causal mechanisms for the association between diabetes and cancer are not clear, potential risk factors common to both are recognized, including demographic (age, sex, race/ethnicity), genetic, and lifestyle-related (obesity, diet, physical activity, tobacco or alcohol consumption) risk factors. Potential mechanisms for a possible biologic link between diabetes and cancer include insulin resistance, hyperinsulinemia, hyperglycemia, and chronic inflammation $(5,6)$. Most empirical studies focus on examining the intervention effect of glucose-lowering medication therapies (metformin, thiazolidinediones, sulfonylureas) on cancer risks or cancer prognosis, which in turn may influence cancerspecific mortality. However, the results regarding associations 
with cancer risk are mixed (3-5). Additional studies examined primarily the association between single healthy lifestyle choices (weight control, healthy diet, physical activity) and the risks of certain types of cancer $(5,7)$. To the best of our knowledge, few studies have investigated the extent to which integrated interventions through a comprehensive and multidisciplinary diabetes management program might mitigate cancer risks and cancer mortality.

Pay-for-performance (P4P) or value-based purchasing programs have been embraced by many developed nations as a strategic tool to stimulate delivery of long-term, multidisciplinary diabetes management and to allow investment of less money on incentives while efficiently improving diabetes care quality $(8-10)$. For example, the United Kingdom's Quality and Outcome Framework and Australia's P4P program pay bonuses to reward improvements in care for diabetes patients $(9,11)$. In Taiwan, a diabetes P4P program was implemented nationwide by Taiwan's National Health Insurance Administration (NHIA) at the end of 2001 to provide comprehensive diabetes management by following the American Diabetes Association's clinical practice guidelines (12). Comprehensive care through diabetes $\mathrm{P} 4 \mathrm{P}$ programs may enhance quality of care and prevent or delay vascular complications $(12,13)$ or reduce risks of all-cause mortality in patients with diabetes (13). However, evidence of whether comprehensive diabetes care through a $\mathrm{P} 4 \mathrm{P}$ program has any effect on incidence of types of cancer, or competing risks for cancer-specific or diabetesrelated death, is limited.

This study aimed to examine the effects of comprehensive diabetes care provided through a nationwide diabetes $\mathrm{P} 4 \mathrm{P}$ program in Taiwan on risks of cancer incidence and mortality among patients with type 2 diabetes. We hypothesized that modifying lifestyle-related risk factors with a comprehensive diabetes $\mathrm{P} 4 \mathrm{P}$ program or administration of glucose-lowering medication therapies may prevent or delay incident cancer. We conducted an observational intervention and comparison cohort study using data from 3 longitudinal population-based databases in Taiwan to examine the extent to which the $\mathrm{P} 4 \mathrm{P}$ program and other risk factors were associated with cancer incidence and competing causes of death (cancerspecific and diabetes-related) in patients with type 2 diabetes who enrolled in the P4P program compared with a group of diabetes patients who did not participate.

\section{Methods}

A diabetes P4P program was implemented by Taiwan's NHIA in 2001 to improve the quality of health care for diabetes patients. The program consists of several features (12). First, patients with diabetes who have at least 2 outpatient visits within 3 months in the same health care institution are eligible to enroll in the $\mathrm{P} 4 \mathrm{P}$ program. Second, only physicians who specialize in metabolic disorders or endocrinology or who attend a training program for diabetes care are eligible to participate in and voluntarily enroll patients into this $\mathrm{P} 4 \mathrm{P}$ program. Third, medical care teams are expected to work as coordinated physician-led multidisciplinary teams adhering to the American Diabetes Association's clinical guidelines. Fourth, in addition to regular and usual care, P4P patients receive extra comprehensive care, including medical history assessment, physical examination, laboratory evaluation, management plan evaluation, self-management and health education. Finally, participating $\mathrm{P} 4 \mathrm{P}$ physicians receive extra incentive payments in addition to regular physician fees depending on incentive targets for improving process (eg, documented hemoglobin $\mathrm{A} 1 \mathrm{c}[\mathrm{HbA} 1 \mathrm{c}]$ or low-density lipoprotein tests) and intermediate outcomes (eg, higher percentages of patients with controlled $\mathrm{HbA1c}$ or low-density lipoprotein) $(12,14)$.

\section{Study design and data source}

We conducted a longitudinal observational intervention and comparison cohort study using 3 population-based databases in Taiwan. One database was the 2-million-sample longitudinal health and welfare database from 2000 through 2010 , a nationally representative random sample of NHIA beneficiaries in 2005, from which we obtained information on patient comorbid conditions, health provider characteristics, and billing variables to identify patients enrolled in the $\mathrm{P} 4 \mathrm{P}$ program. The second was a database containing death registry data from 2000 through 2010, which provides accurate death dates and cause-of-death information. The third was a national cancer registry, from which we obtained accurate cancer diagnosis data from 1979 through 2010. The 3 databases were linked with encrypted patient identifiers, and all data analysis was completed in the Health and Welfare Data Science Center, the Ministry of Health and Welfare in Taiwan in 2015 and 2016. This study was approved by the institutional review board at Kaohsiung Medical University Hospital.

\section{Study population}

Diabetes patients were identified by a primary diabetes diagnosis code (International Classification of Diseases, Ninth Revision, Clinical Modification [ICD-9-CM], code 250) on at least 2 outpatient claims or at least 1 inpatient claim in each year during the patient identification period from 2003 through 2005. We first excluded patients with type 1 diabetes (ICD-9-CM codes 250.x 1 or $250 . \times 3$ ), because they made up less than $3 \%$ of diabetes patients, and patients aged younger than 18 years on the date of first diabetes diagnosis during the patient identification period. Among eligible diabetes patients, we then identified newly enrolled P4P patients with at least 2 billing codes with "P14x" (internal code)

\footnotetext{
The opinions expressed by authors contributing to this journal do not necessarily reflect the opinions of the U.S. Department of Health and Human Services, the Public Health Service, the Centers for Disease Control and Prevention, or the authors' affiliated institutions.
} 
for different office visits in the claims during the patient identification period and defined the date of first enrollment as the index date. We identified non-P4P diabetes patients for the comparison groups who were not found to be enrolled in the P4P program during the patient identification period or the follow-up period. Given that non-P4P patients lacked P4P enrollment index dates, we randomly assigned index dates based on the dynamic frequency distribution of time exposure to the $\mathrm{P} 4 \mathrm{P}$ intervention from the $\mathrm{P} 4 \mathrm{P}$ group (15). Using the cancer registry database, we excluded patients with any cancer diagnosis from the first year of the cancer registry in 1979 to the index date. Totals of 9,450 P4P and 32,923 non-P4P patients with diabetes were identified.

Propensity score matching (PSM) was used to determine adequate comparison groups to avoid potential confounding by selection bias and confounding factors. We created propensity scores that predicted the probability of enrollment into the diabetes P4P program in a logistic regression model. The PSM caliper matching method with 1-to-1 match was used to match intervention group with comparison group members based on propensity score $(16,17)$. This approach finds the nearest distance of probabilities for the estimated propensity score to determine the best matches with the smallest standard deviations between intervention and comparison groups. If more than 1 potential comparison group member has the same propensity score as an intervention group member, the algorithm randomly selects one for inclusion in the comparison group $(16,17)$. We also calculated standardized differences of covariates between phases, and all differences less than $10 \%$ indicated acceptable matching (18). Covariates included demographic characteristics (age, sex, highest level of education, urban or rural residence), baseline comorbid conditions (eg, the diabetes complications severity index [DCSI] [19] and chronic illness with complexity index [CIC] [20]), baseline antidiabetes drug use from 1 year before to the index date, and the most frequent health institution characteristics (accreditation level and geographic location). After PSM matching, 9,329 P4P and non-P4P matched pairs were studied.

\section{Variable definitions}

The major end points were risks of cancer incidence and all-cause, cancer-specific, and diabetes-related mortality, with outcomes for $\mathrm{P} 4 \mathrm{P}$ and non-P4P patients being compared. Overall cancer and common types of cancer (eg, breast, colorectal, liver) among diabetes patients were identified using ICD-9-CM diagnosis codes in the national cancer registry data. Cancer-specific and diabetes-related mortality were identified from causes of death based on the ICD-9 and ICD-10 diagnosis codes in the national death registry data. We defined diabetes-related death given the major risks of diabetes complications and prognosis that may cause death, including diabetes mellitus, macrovascular complications (eg, cardi- ovascular, cerebrovascular, and peripheral vascular diseases) and microvascular complications (eg, nephropathy and neuropathy diseases) (19). To compare groups, we followed each P4P and nonP4P patient from the index date to the first event date, death date, or study end date on December 31, 2010, whichever came first. We then calculated and compared total person-years for each patient and incidence and mortality per 1,000 person-years between $\mathrm{P} 4 \mathrm{P}$ and non-P4P patients with diabetes given different end points.

Several baseline characteristics that may affect outcomes were included as control variables. Patient demographic covariates included age, sex, highest level of education, and urban or rural residence. The DCSI and CIC within 1 year before the index date were used to measure baseline comorbidity. These indexes are frequently used in studies $(19,20)$. The DCSI has 7 categories of complications by ICD-9-CM code: cardiovascular complications, nephropathy, retinopathy, peripheral vascular disease, stroke, neuropathy, and metabolic disorders. The CIC index includes nondiabetes physical illness complexity, diabetes-related complexity, and mental illness or substance abuse complexity. We excluded cancer and diabetes-related complexity when constructing the CIC index to avoid the duplication of the comorbidity identified by the DCSI and cancer disease (21). Additionally, we controlled for frequently prescribed antidiabetes medications used during the follow-up period on the basis of the Anatomical Therapeutic Chemical Classification System (ATC codes), measured as 0 or 1 binary variables for identifying whether metformin (ATC code A10BA), sulfonylureas (SUs, ATC code A10BB), thiazolidinediones (TZDs, ATC code A10BG), or a glucosidase inhibitors (AGIs, ATC code A10BF) were prescribed.

Because the $\mathrm{P} 4 \mathrm{P}$ program requires health staff to work as a team and cost structures may differ by health institution, the characteristics of the most frequently seen health care provider were included to identify the resources and capacities of individual health care institutions; characteristics included accreditation levels (medical center, regional hospital, local hospital, or clinic) and geographic locations (Taipei, northern area, central area, southern area, Kao-Ping, or eastern area).

\section{Statistical analysis}

In addition to the PSM approach, we used multivariable Cox proportional hazard models to estimate the likelihood of all-cause mortality comparing matched $\mathrm{P} 4 \mathrm{P}$ and non-P4P patients. We tested the proportional hazard assumption based on scaled Schoenfeld residuals after fitting Cox proportional hazard models and found no evidence that the proportional-hazard assumption was violated (22). To account for the competing causes of death, cancerspecific death, and diabetes-related death and for the competing risks of cancer incidence and death, we created competing risk re-

The opinions expressed by authors contributing to this journal do not necessarily reflect the opinions of the U.S. Department of Health and Human Services, the Public Health Service, the Centers for Disease Control and Prevention, or the authors' affiliated institutions. 
gression models; we calculated subdistribution hazard ratios (SHRs) and 95\% confidence intervals (CIs) (23). Potential confounding variables (Table 1) were controlled for. Patients were clustered within matched pairs and health care institutions to control for unequal error variances across matched pairs and health care providers. All statistical operations were performed by using SAS version 9.4 (SAS Institute, Inc) and Stata version SE 13 (StataCorp LP). A $P$ value of less than .05 was considered significant.

\section{Results}

Before PSM 1-to-1 matching, the P4P group and the non-P4P group differed significantly $(P<.001)$ by several characteristics (Table 1). After matching, all baseline characteristics between the 2 matched groups were similar. Of the P4P patients, $48.0 \%$ were men and had a mean age of 60.8 years; $38.6 \%$ had an education level of high school or above, and $46.7 \%$ lived in urban areas. Mean DCSI was 1.16 and mean was CIC 1.09. Baseline antidiabetes drug use did not differ significantly between P4P and non$\mathrm{P} 4 \mathrm{P}$ patients. Compared with non-P4P patients, $\mathrm{P} 4 \mathrm{P}$ patients received more metformin, TZDs, and AGIs during follow-up $(P<$ $.001)$.

Table 2 compares total person-years and crude cancer incidence and mortality per 1,000 person-years for various end points between P4P and non-P4P patients. Risks of overall cancer incidence were not significantly associated with the P4P program but were associated with use of antidiabetes medication, particularly metformin (aSHR, 0.58: 95\% CI, 0.50-0.67), TZDs (aSHR, 0.78; 95\% CI, 0.70-0.86), and AGIs (aSHR, 0.62; 95\% CI, 0.55-0.69) (Table 3). P4P patients had lower risks of all-cause mortality (aSHR, 0.59; 95\% CI, 0.55-0.63), cancer-specific mortality (aSHR, 0.85; 95\% CI, 0.73-1.00), and diabetes-related mortality (aSHR, 0.54; 95\% CI, 0.49-0.60) than non-P4P patients with diabetes (Figure).

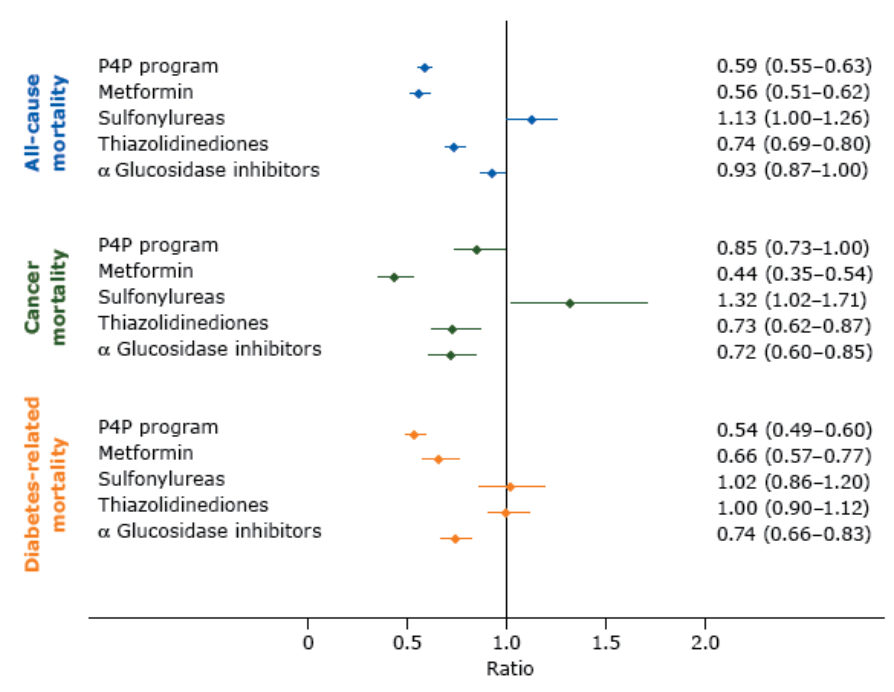

Figure. Adjusted model results and 95\% confidence intervals for the effects of a pay-for-performance program (P4P) and prescribed antidiabetes medications on the risks of all-cause, cancer, and diabetes-related mortality in Taiwan. Competing risk regression models were used to analyze the effects of P4P and drug effects on risks of cancer-specific and diabetes-related mortality and the adjusted subdistribution hazard ratios were calculated. A Cox proportionate hazard model was used to analyze all-cause mortality and the adjusted hazard ratios were calculated. Potential confounders that were controlled for were age, sex, highest level of education, rural or urban residence, baseline comorbidity (diabetes complications severity index and chronic illness with complexity), antidiabetes drug use (metformin, sulfonylureas, thiazolidinediones, $\alpha$ glucosidase inhibitors), and health care facility characteristics (accreditation level and geographic regions).

\section{Discussion}

Recent literature has focused on cancer risk or mortality with various diabetes treatments, given the potential biologic link or common risk factors for the observed associations between type 2 diabetes and cancer (3-6). However, studies on the effect of diabetes control through a comprehensive diabetes $\mathrm{P} 4 \mathrm{P}$ program on cancer risks or mortality were inconclusive $(4-6,24)$. Overall, our findings indicated that the diabetes P4P program was not significantly associated with lower risks of cancer incidence, but it was associated with lower risks of all-cause mortality, cancer-specific mortality, and diabetes-related mortality.

With all other variables constant, our findings suggest that the diabetes $\mathrm{P} 4 \mathrm{P}$ program may be less likely to affect the risk of overall or specific cancer incidence while several types of glucose-lowering therapies (metformin, TZDs, AGIs) may have a protective effect, consistent with results of observational studies $(25,26)$. The nonsignificant association between the P4P program and cancer incidence might be explained by several reasons. First, compared with medications that affect the potential biologic link between

\footnotetext{
The opinions expressed by authors contributing to this journal do not necessarily reflect the opinions of the U.S. Department of Health and Human Services, the Public Health Service, the Centers for Disease Control and Prevention, or the authors' affiliated institutions.
} 
diabetes and cancer risk within a shorter period, medications used over a longer follow-up period may be required for a comprehensive disease management program to demonstrate reduction in risk. Second, previous studies found that, after enrollment, P4P patients had significantly more outpatient visits, greater expense, and higher usage of guideline-recommended services (including preventive services) than non-P4P patients (21). Thus, P4P patients may receive more cancer screening tests and have more early cancer detection and treatment. The potential effect of a comprehensive disease management program on cancer risk might be mitigated. Future study is suggested to examine the effect of a diabetes $\mathrm{P} 4 \mathrm{P}$ program on incidence of specific cancers.

Alternatively, our findings suggest that the diabetes P4P program not only has a protective effect on all-cause mortality and diabetes-related mortality but also influences cancer-specific mortality among incident cancer patients. Cancer survival outcomes among P4P patients might be explained by several reasons. First, the diabetes P4P program in Taiwan requires participating health care providers to adhere to the American Diabetes Association's clinical practice guidelines. The guidelines are consistent with the nutrition and physical activity guidelines for cancer survivors suggested by the American Cancer Society, including recommendations for psychosocial and social assessment and care, preventive care (vaccinations, screening), lifestyle changes, diet, physical activities, and obesity management (27). As studies by Chiao et al (28) and Calip et al (29) suggested, well diabetes care and glucose control before cancer diagnosis (colorectal, breast), which persisted after diagnosis, may have moderated the mortality effect of diabetes in newly diagnosed cancer patients $(28,29)$. Second, in contrast to the uncertain relationship between glucose-lowering treatments and cancer incidence, previous studies supported beneficial effects of antidiabetes medications, along with glycemic control, possibly affecting cancer treatments, which may in turn influence cancer-specific mortality $(4,25,29)$. We observed that $\mathrm{P} 4 \mathrm{P}$ patients tended to have more opportunity to receive oral glucose-lowering medications (metformin, TZDs, AGIs) than non-P4P patients during follow-up (all $P<.001$; Table1). Consistent with other studies, our study (Figure) indicated that metformin (aSHR, 0.44: 95\% CI, 0.35-0.54), TZDs (aSHR, 0.73; 95\% CI, $0.62-0.87$ ), and AGIs (aSHR, 0.72; 95\% CI, 0.60-0.85) were associated with lower risks of cancer-specific mortality in incident cancer patients.

This study has several limitations. First, given the limitation of our study data periods in the administrative claims from 2000, we could not track the number of years since diabetes was diagnosed or identify whether patients were newly diagnosed. However, we could track the time of cancer diagnosis through the cancer registry data set since 1979 as the washout period for exclusion cri- teria. Second, some unobservable confounders for individual patients (eg, lifestyle, prescription adherence, illness experience, smoking status, body weight, psychological and social assessment) were unavailable in the secondary database. Although these baseline confounding factors were not part of the study design and we assumed that all characteristics related to health outcomes in the P4P program were covered by the measured variables among $\mathrm{P} 4 \mathrm{P}$ and non-P4P patients, caution is necessary when interpreting the effect of the P4P program on mortality. Third, given our study design, we observed cancer incidence and mortality events over a 5-year period. A greater effect might have been found with a longer observation period. Nevertheless, our 5-year observation period was considered sufficient to evaluate and compare various quality improvement interventions (30). Finally, the data we used were obtained from patients with diabetes in Taiwan, so results may not be generalized to other P4P programs in other countries.

Despite these limitations, this study addressed the issue of whether integrated interventions through a comprehensive and multidisciplinary diabetes $\mathrm{P} 4 \mathrm{P}$ program might mitigate cancer risks and mortality. Compared with patients with diabetes not enrolled in the P4P program, P4P patients had lower risk of all-cause mortality, cancer-specific mortality, and diabetes-related mortality, but the groups did not differ in overall risks of incident cancer. Our findings provide evidence of the potential benefit of diabetes P4P programs in reducing risks of all-cause mortality and competing causes of death attributable to cancer-specific and diabetes-related mortality among type 2 diabetes patients.

\section{Acknowledgments}

This study was supported by the Ministry of Science and Technology (MOST-103-2314-B-037-001 and MOST 105-2314-B-037063).

We assure that each author meets authorship requirements. None of the authors has a conflict of interest with regard to this manuscript.

Specific contributions to this work: Conception or design of the work, the acquisition, analysis: H.H.M. Interpretation of data for the work: H.H.M. and J.S.H. Revising it critically: H.H.M., J.S.H., S.S.J., H.C.C., and C.T.L. Final approval: H.H.M., J.S.H., S.S.J., H.C.C., and C.T.L.

\section{Author Information}

Corresponding Author: Hui-Min Hsieh, PhD, Associate Professor, Kaohsiung Medical University, Kaohsiung Medical University

The opinions expressed by authors contributing to this journal do not necessarily reflect the opinions of the U.S. Department of Health and Human Services, the Public Health Service, the Centers for Disease Control and Prevention, or the authors' affiliated institutions. 
Hospital, 100 Shin-Chuan 1st Rd, Kaohsiung, Taiwan 80708. Telephone: 886-7-3121101 ex. 2141, then 45. Email: hsiehhm@gmail.com.

Author Affiliations: ${ }^{1}$ Department of Public Health, Kaohsiung Medical University, Kaohsiung, Taiwan. ${ }^{2}$ Department of Medical Research, Kaohsiung Medical University Hospital, Kaohsiung, Taiwan. ${ }^{3}$ Department of Internal Medicine, Kaohsiung Municipal Ta-Tung Hospital, Kaohsiung Medical University, Kaohsiung, Taiwan. ${ }^{4}$ Graduate Institute of Medical Genetics, Kaohsiung Medical University, Kaohsiung, Taiwan. ${ }^{5}$ Division of Endocrinology and Metabolism, Kaohsiung Medical University, Kaohsiung, Taiwan. ${ }^{6}$ Department of Healthcare Administration and Medical Informatics, Kaohsiung Medical University, Kaohsiung, Taiwan. ${ }^{7}$ Research Education and Epidemiology Center, Changhua Christian Hospital, Changhua, Taiwan. ${ }^{8}$ Department of Health Promotion and Health Education, National Taiwan Normal University, Taipei, Taiwan.

\section{References}

1. International Diabetes Federation. IDF diabetes atlas. 6th edition. 2013. http://www.idf.org/sites/default/files/Atlasposter-2014_EN.pdf. Assessed April 17, 2015.

2. Fowler MJ. Microvascular and macrovascular complications of diabetes. Clin Diabetes 2008;26(2):77-82.

3. Johnson JA, Carstensen B, Witte D, Bowker SL, Lipscombe L, Renehan AG; Diabetes and Cancer Research Consortium. Diabetes and cancer (1): evaluating the temporal relationship between type 2 diabetes and cancer incidence. Diabetologia 2012;55(6):1607-18.

4. Renehan AG, Yeh HC, Johnson JA, Wild SH, Gale EA, Møller $\mathrm{H}$; Diabetes and Cancer Research Consortium. Diabetes and cancer (2): evaluating the impact of diabetes on mortality in patients with cancer. Diabetologia 2012;55(6):1619-32.

5. Giovannucci E, Harlan DM, Archer MC, Bergenstal RM, Gapstur SM, Habel LA, et al. Diabetes and cancer: a consensus report. Diabetes Care 2010;33(7):1674-85.

6. Shikata K, Ninomiya T, Kiyohara Y. Diabetes mellitus and cancer risk: review of the epidemiological evidence. Cancer Sci 2013;104(1):9-14.

7. Larsson SC, Wolk A. Obesity and colon and rectal cancer risk: a meta-analysis of prospective studies. Am J Clin Nutr 2007; 86(3):556-65.

8. Beich J, Scanlon DP, Ulbrecht J, Ford EW, Ibrahim IA. The role of disease management in pay-for-performance programs for improving the care of chronically ill patients. Med Care Res Rev 2006;63(1,Suppl):96S-116S.
9. Campbell SM, Reeves D, Kontopantelis E, Sibbald B, Roland M. Effects of pay for performance on the quality of primary care in England. N Engl J Med 2009;361(4):368-78.

10. de Bruin SR, Baan CA, Struijs JN. Pay-for-performance in disease management: a systematic review of the literature. BMC Health Serv Res 2011;11(1):272.

11. Greene J. An examination of pay-for-performance in general practice in Australia. Health Serv Res 2013;48(4):1415-32.

12. Hsieh HM, Lin TH, Lee IC, Huang CJ, Shin SJ, Chiu HC. The association between participation in a pay-for-performance program and macrovascular complications in patients with type 2 diabetes in Taiwan: a nationwide population-based cohort study. Prev Med 2016;85:53-9.

13. Kornelius E, Chiou JY, Yang YS, Lu YL, Peng CH, Huang $\mathrm{CN}$. The Diabetes Shared Care Program and risks of cardiovascular events in type 2 diabetes. Am J Med 2015; 128(9):977-85.e3.

14. Hsieh HM, Tsai SL, Shin SJ, Mau LW, Chiu HC. Costeffectiveness of diabetes pay-for-performance incentive designs. Med Care 2015;53(2):106-15.

15. Harvey R, Jankus DD, Mosley D, UnitedHealthcare. Random assignment of proxy event dates to unexposed individuals in observational studies: an automated technique using SAS. 2012. http://www.mwsug.org/proceedings/2012/PH/MWSUG2012-PH02.pdf. Assessed November 12, 2014.

16. Austin PC. The performance of different propensity-score methods for estimating relative risks. J Clin Epidemiol 2008; 61(6):537-45.

17. Dehejia RH, Wahba S. Propensity score-matching methods for nonexperimental causal studies. Rev Econ Stat 2002; 84(1):151-61.

18. Austin PC. An introduction to propensity score methods for reducing the effects of confounding in observational studies. Multivariate Behav Res 2011;46(3):399-424.

19. Young BA, Lin E, Von Korff M, Simon G, Ciechanowski P, Ludman EJ, et al. Diabetes complications severity index and risk of mortality, hospitalization, and healthcare utilization. Am J Manag Care 2008;14(1):15-23.

20. Meduru P, Helmer D, Rajan M, Tseng CL, Pogach L, Sambamoorthi U. Chronic illness with complexity: implications for performance measurement of optimal glycemic control. J Gen Intern Med 2007;22(S3,Suppl 3):408-18.

21. Cheng SH, Lee TT, Chen CC. A longitudinal examination of a pay-for-performance program for diabetes care: evidence from a natural experiment. Med Care 2012;50(2):109-16.

22. Grambsch PM, Therneau TM. Proportional hazards tests and diagnostics based on weighted residuals. Biometrika 1994; 81(3):515-26.

\footnotetext{
The opinions expressed by authors contributing to this journal do not necessarily reflect the opinions of the U.S. Department of Health and Human Services, the Public Health Service, the Centers for Disease Control and Prevention, or the authors' affiliated institutions.
} 
23. Fine JP, Gray RJ. A proportional hazard model for the subdistribution of a competing risk. J Am Stat Assoc 1999; 94(446):496-509.

24. Emerging Risk Factors Collaboration; Seshasai SR, Kaptoge S, Thompson A, Di Angelantonio E, Gao P, et al. Diabetes mellitus, fasting glucose, and risk of cause-specific death. N Engl J Med 2011;364(9):829-41. Erratum in N Engl J Med 2011;364(13):1281.

25. Gandini S, Puntoni M, Heckman-Stoddard BM, Dunn BK, Ford L, DeCensi A, et al. Metformin and cancer risk and mortality: a systematic review and meta-analysis taking into account biases and confounders. Cancer Prev Res (Phila) 2014; 7(9):867-85.

26. Monami M, Dicembrini I, Mannucci E. Thiazolidinediones and cancer: results of a meta-analysis of randomized clinical trials. Acta Diabetol 2014;51(1):91-101.

27. Runowicz CD, Leach CR, Henry NL, Henry KS, Mackey HT, Cowens-Alvarado RL, et al. American Cancer Society/ American Society of Clinical Oncology breast cancer survivorship care guideline. J Clin Oncol 2016;34(6):611-35.

28. Chiao EY, Nambi PV, Naik AD. The impact of diabetes process and outcome quality measures on overall survival in patients with co-morbid colorectal cancer. J Cancer Surviv 2010;4(4):381-7. Erratum in J Cancer Surviv 2011;5(1):113.

29. Calip GS, Hubbard RA, Stergachis A, Malone KE, Gralow JR, Boudreau DM. Adherence to oral diabetes medications and glycemic control during and following breast cancer treatment. Pharmacoepidemiol Drug Saf 2015;24(1):75-85.

30. Welch HG, Schwartz LM, Woloshin S. Are increasing 5-year survival rates evidence of success against cancer? JAMA 2000; 283(22):2975-8. 


\section{Tables}

Table 1. Patient and Health Care Institution Characteristics Among P4P and Non-P4P Patients With Type 2 Diabetes, Taiwan

\begin{tabular}{|c|c|c|c|c|c|c|c|}
\hline \multirow[b]{2}{*}{ Variable } & \multicolumn{3}{|c|}{ Before PSM Matching } & \multicolumn{4}{|c|}{ After PSM Matching } \\
\hline & P4P & Non-P4P & $P$ Value & P4P & Non-P4P & $P$ Value & $\begin{array}{l}\text { Standardized } \\
\text { Difference, } \%^{a}\end{array}$ \\
\hline No. & 9,450 & 32,923 & NA & 9,329 & 9,329 & & NA \\
\hline \multicolumn{8}{|c|}{ Patient Characteristics } \\
\hline \multicolumn{8}{|l|}{ Sex, no. $(\%)^{b}$} \\
\hline Male & $4,511(47.7)$ & $16,461(50.0)$ & \multirow{2}{*}{$<.001$} & $4,475(48.0)$ & $4,504(48.3)$ & \multirow{2}{*}{.67} & 0.62 \\
\hline Female & 4,939 (52.3) & $16,462(50.0)$ & & $4,854(52.0)$ & $4,825(51.7)$ & & 0.62 \\
\hline Age, mean (SD), $y^{b}$ & $60.7(11.4)$ & $62.9(12.1)$ & $<.001$ & $60.8(11.4)$ & $60.7(12.3)$ & .62 & 0.93 \\
\hline \multicolumn{8}{|l|}{ Age category, no. (\%), y } \\
\hline$<55$ & $3,039(32.2)$ & $9,152(27.8)$ & \multirow{4}{*}{$<.001$} & 2,966 (31.8) & 3,229 (34.6) & \multirow{4}{*}{$<.001$} & 5.99 \\
\hline $55-64$ & $2,840(30.1)$ & $8,430(25.6)$ & & $2,806(30.1)$ & 2,507 (26.9) & & 7.12 \\
\hline $65-74$ & $2,583(27.3)$ & $9,613(29.2)$ & & $2,572(27.6)$ & $2,367(25.4)$ & & 4.99 \\
\hline$\geq 75$ & $988(10.5)$ & $5,728(17.4)$ & & 985 (10.6) & $1,226(13.1)$ & & 7.99 \\
\hline \multicolumn{8}{|c|}{ Highest level of education, no. (\%) } \\
\hline Illiterate & $1,276(13.5)$ & $5,396(16.4)$ & \multirow{4}{*}{$<.001$} & $1,268(13.6)$ & $1,282(13.7)$ & \multirow{4}{*}{.86} & 0.44 \\
\hline Elementary school & $4,515(47.8)$ & $15,540(47.2)$ & & 4,465 (47.9) & $4,437(47.6)$ & & 0.60 \\
\hline High school & $2,797(29.6)$ & $9,133(27.7)$ & & $2,747(29.5)$ & 2,785 (29.9) & & 0.88 \\
\hline $\begin{array}{l}\text { College or university and } \\
\text { above }\end{array}$ & $862(9.2)$ & $2,854(8.7)$ & & 849 (9.1) & $825(8.8)$ & & 0.91 \\
\hline \multicolumn{8}{|l|}{ Residence, no. (\%) ${ }^{b}$} \\
\hline Urban area & $4,394(46.5)$ & $16,264(49.4)$ & \multirow{3}{*}{$<.001$} & $4,354(46.7)$ & $4,401(47.2)$ & \multirow{3}{*}{.75} & 1.02 \\
\hline Suburban area & $3,976(42.1)$ & 12,875 (39.1) & & $3,910(41.9)$ & $3,886(41.7)$ & & 0.51 \\
\hline Rural area & $1,080(11.4)$ & $3,784(11.5)$ & & $1,065(11.4)$ & $1,042(11.2)$ & & 0.79 \\
\hline \multicolumn{8}{|l|}{ Baseline comorbidity } \\
\hline DCSI, mean (SD) ${ }^{b}$ & $1.16(1.34)$ & $1.15(1.46)$ & .84 & $1.16(1.34)$ & $1.15(1.45)$ & .72 & 0.72 \\
\hline \multicolumn{8}{|l|}{ DCSI category, no. (\%) } \\
\hline 0 & $3,852(40.8)$ & $14,928(45.3)$ & $<.001$ & $3,803(40.8)$ & $4,188(44.9)$ & $<.001$ & 8.33 \\
\hline
\end{tabular}

Abbreviations: CIC, chronic illness with complexity index (20); DCSI, diabetes complications severity index (19); NA, not applicable; P4P, pay-for-performance program; PSM, propensity score matching.

${ }^{\text {a }}$ Standardized difference was used to compare the balancing for the mean or frequencies of a covariate that were included in the propensity score matching process (18). Standardized difference was calculated to evaluate the efficiency of PSM.

${ }^{\mathrm{b}}$ These variables were used in the PSM.

${ }^{\mathrm{c}}$ Baseline antidiabetes drug use was measured if patients were prescribed the selected medications within 1 year before index date; patients could use more than 1 drug.

${ }^{d}$ Follow-up antidiabetes drug use was measured if patients were prescribed the selected medications between the index date and the study end date (December 31, 2010), cancer occurrence, or death date, whichever came first; patients could use more than 1 drug. This set of variables was not included in the PSM regression.

${ }^{\mathrm{e}}$ Geographic region categories were based on the branches of the National Health Insurance Administration in which the hospitals were located. 
(continued)

Table 1. Patient and Health Care Institution Characteristics Among P4P and Non-P4P Patients With Type 2 Diabetes, Taiwan

\begin{tabular}{|c|c|c|c|c|c|c|c|}
\hline \multirow[b]{2}{*}{ Variable } & \multicolumn{3}{|c|}{ Before PSM Matching } & \multicolumn{4}{|c|}{ After PSM Matching } \\
\hline & P4P & Non-P4P & $P$ Value & P4P & Non-P4P & $P$ Value & $\begin{array}{l}\text { Standardized } \\
\text { Difference, \% }\end{array}$ \\
\hline 1 & $2,666(28.2)$ & $7,800(23.7)$ & & $2,631(28.2)$ & $2,273(24.4)$ & & 8.73 \\
\hline$\geq 2$ & $2,932(31.0)$ & $10,195(31.0)$ & & 2,895 (31.0) & $2,868(30.7)$ & & 0.63 \\
\hline $\mathrm{ClC}$, mean $(\mathrm{SD})^{\mathrm{b}}$ & $1.10(0.95)$ & $1.11(0.98)$ & .08 & $1.09(0.95)$ & $1.09(0.98)$ & .99 & 0 \\
\hline \multicolumn{8}{|c|}{ CIC category, no. (\%) } \\
\hline 0 & $2,903(30.7)$ & $10,258(31.2)$ & \multirow{3}{*}{.13} & $2,871(30.8)$ & 2,972 (31.9) & \multirow{3}{*}{.25} & 2.33 \\
\hline 1 & $3,567(37.8)$ & $12,058(36.6)$ & & $3,519(37.7)$ & $3,437(36.8)$ & & 1.82 \\
\hline$\geq 2$ & $2,980(31.5)$ & $10,607(32.2)$ & & 2,939 (31.5) & $2,920(31.3)$ & & 0.43 \\
\hline \multicolumn{8}{|c|}{ Antidiabetes Drug Use at Baseline, No. (\%) ${ }^{c}$} \\
\hline \multicolumn{8}{|l|}{ Metformin $^{\text {b }}$} \\
\hline No & $2,217(23.5)$ & $11,127(33.8)$ & \multirow{2}{*}{$<.001$} & $2,216(23.8)$ & $2,191(23.5)$ & \multirow{2}{*}{.67} & 0.61 \\
\hline Yes & $7,233(76.5)$ & $21,796(66.2)$ & & $7,113(76.3)$ & $7,138(76.5)$ & & 0.61 \\
\hline \multicolumn{8}{|l|}{ Sulfonylureas ${ }^{b}$} \\
\hline No & $1,590(16.8)$ & $6,373(19.4)$ & \multirow{2}{*}{$<.001$} & $1,581(17.0)$ & $1,601(17.2)$ & \multirow{2}{*}{.70} & 0.56 \\
\hline Yes & $7,860(83.2)$ & $26,550(80.6)$ & & $7,748(83.1)$ & $7,728(82.8)$ & & 0.56 \\
\hline \multicolumn{8}{|c|}{ Thiazolidinediones $^{\mathrm{b}}$} \\
\hline No & $7,497(79.3)$ & $28,604(86.9)$ & \multirow{2}{*}{$<.001$} & 7,453 (79.9) & $7,500(80.4)$ & \multirow{2}{*}{.39} & 1.25 \\
\hline Yes & $1,953(20.7)$ & $4,319(13.1)$ & & $1,876(20.1)$ & 1,829 (19.6) & & 1.25 \\
\hline \multicolumn{8}{|c|}{$\alpha$ Glucosidase inhibitors $^{b}$} \\
\hline No & $7,982(84.5)$ & $29,774(90.4)$ & \multirow{2}{*}{$<.001$} & $7,928(85.0)$ & $7,929(85.0)$ & \multirow{2}{*}{.98} & 0.03 \\
\hline Yes & $1,468(15.5)$ & $3,149(9.6)$ & & $1,401(15.0)$ & $1,400(15.0)$ & & 0.03 \\
\hline \multicolumn{8}{|c|}{ Antidiabetes Drug Use During Follow-up, No. (\%) } \\
\hline \multicolumn{8}{|l|}{ Metformin } \\
\hline No & $708(7.5)$ & $4,764(14.5)$ & \multirow{2}{*}{$<.001$} & $705(7.6)$ & $1,092(11.7)$ & \multirow{2}{*}{$<.001$} & NA \\
\hline Yes & $8,742(92.5)$ & $28,159(85.5)$ & & $8,624(92.4)$ & $8,237(88.3)$ & & NA \\
\hline \multicolumn{8}{|l|}{ Sulfonylureas } \\
\hline No & $854(9.0)$ & $3,740(11.4)$ & \multirow{2}{*}{$<.001$} & $847(9.1)$ & $972(10.4)$ & \multirow{2}{*}{.002} & NA \\
\hline Yes & $8,596(91.0)$ & $29,183(88.6)$ & & $8,482(90.9)$ & $8,357(89.6)$ & & NA \\
\hline
\end{tabular}

Abbreviations: CIC, chronic illness with complexity index (20); DCSI, diabetes complications severity index (19); NA, not applicable; P4P, pay-for-performance program; PSM, propensity score matching.

${ }^{\text {a }}$ Standardized difference was used to compare the balancing for the mean or frequencies of a covariate that were included in the propensity score matching process (18). Standardized difference was calculated to evaluate the efficiency of PSM.

${ }^{\mathrm{b}}$ These variables were used in the PSM.

${ }^{c}$ Baseline antidiabetes drug use was measured if patients were prescribed the selected medications within 1 year before index date; patients could use more than 1 drug.

${ }^{d}$ Follow-up antidiabetes drug use was measured if patients were prescribed the selected medications between the index date and the study end date (December 31, 2010), cancer occurrence, or death date, whichever came first; patients could use more than 1 drug. This set of variables was not included in the PSM regression.

${ }^{\mathrm{e}}$ Geographic region categories were based on the branches of the National Health Insurance Administration in which the hospitals were located. 
(continued)

Table 1. Patient and Health Care Institution Characteristics Among P4P and Non-P4P Patients With Type 2 Diabetes, Taiwan

\begin{tabular}{|c|c|c|c|c|c|c|c|}
\hline \multirow[b]{2}{*}{ Variable } & \multicolumn{3}{|c|}{ Before PSM Matching } & \multicolumn{4}{|c|}{ After PSM Matching } \\
\hline & P4P & Non-P4P & $P$ Value & P4P & Non-P4P & $P$ Value & $\begin{array}{l}\text { Standardized } \\
\text { Difference, } \%^{\mathrm{a}}\end{array}$ \\
\hline \multicolumn{8}{|c|}{ Thiazolidinediones } \\
\hline No & $4,541(48.1)$ & $20,708(62.9)$ & \multirow{2}{*}{$<.001$} & $4,515(48.4)$ & $5,279(56.6)$ & \multirow{2}{*}{$<.001$} & NA \\
\hline Yes & 4,909 (52.0) & $12,215(37.1)$ & & $4,814(51.6)$ & $4,050(43.4)$ & & NA \\
\hline \multicolumn{8}{|c|}{$\alpha$ Glucosidase inhibitors } \\
\hline No & $5,035(53.3)$ & $21,126(64.2)$ & \multirow{2}{*}{$<.001$} & 4,998 (53.6) & $5,637(60.4)$ & \multirow{2}{*}{$<.001$} & NA \\
\hline Yes & $4,415(46.7)$ & $11,797(35.8)$ & & $4,331(46.4)$ & 3,692 (39.6) & & NA \\
\hline
\end{tabular}

Health Care Facility Characteristics

Accreditation level, no. (\%)

\begin{tabular}{|c|c|c|c|c|c|c|c|}
\hline Medical center & 1,915 (20.3) & $8,333(25.3)$ & \multirow{4}{*}{$<.001$} & $1,915(20.5)$ & 1,762 (18.9) & \multirow{4}{*}{.03} & 4.12 \\
\hline Regional hospital & 3,689 (39.0) & $8,132(24.7)$ & & $3,584(38.4)$ & $3,697(39.6)$ & & 2.48 \\
\hline Local hospital & $2,172(23.0)$ & $6,694(20.3)$ & & $2,156(23.1)$ & $2,140(22.9)$ & & 0.40 \\
\hline Clinic & $1,674(17.7)$ & $9,764(29.7)$ & & $1,674(17.9)$ & $1,730(18.5)$ & & 1.55 \\
\hline
\end{tabular}

Geographic region, no. $(\%)^{\text {b,e }}$

\begin{tabular}{|c|c|c|c|c|c|c|c|}
\hline Taipei & $2,535(26.8)$ & $10,068(30.6)$ & \multirow{6}{*}{$<.001$} & $2,535(27.2)$ & $2,584(27.7)$ & \multirow{6}{*}{.65} & 1.19 \\
\hline Northern & $1,263(13.4)$ & $4,838(14.7)$ & & $1,263(13.5)$ & $1,304(14.0)$ & & 1.28 \\
\hline Central & 3,296 (34.9) & $5,361(16.3)$ & & $3,175(34.0)$ & 3,107 (33.3) & & 1.54 \\
\hline Southern & $852(9.0)$ & 4,955 (15.1) & & 852 (9.1) & $839(9.0)$ & & 0.49 \\
\hline Kao-Ping & $1,269(13.4)$ & $6,732(20.5)$ & & 1,269 (13.6) & $1,284(13.8)$ & & 0.47 \\
\hline Eastern & $235(2.5)$ & 969 (2.9) & & 235 (2.5) & $211(2.3)$ & & 1.70 \\
\hline
\end{tabular}

Abbreviations: CIC, chronic illness with complexity index (20); DCSI, diabetes complications severity index (19); NA, not applicable; P4P, pay-for-performance program; PSM, propensity score matching.

${ }^{a}$ Standardized difference was used to compare the balancing for the mean or frequencies of a covariate that were included in the propensity score matching process (18). Standardized difference was calculated to evaluate the efficiency of PSM.

${ }^{\mathrm{b}}$ These variables were used in the PSM.

${ }^{\mathrm{c}}$ Baseline antidiabetes drug use was measured if patients were prescribed the selected medications within 1 year before index date; patients could use more than 1 drug.

${ }^{d}$ Follow-up antidiabetes drug use was measured if patients were prescribed the selected medications between the index date and the study end date (December 31, 2010), cancer occurrence, or death date, whichever came first; patients could use more than 1 drug. This set of variables was not included in the PSM regression.

${ }^{\mathrm{e}}$ Geographic region categories were based on the branches of the National Health Insurance Administration in which the hospitals were located.

The opinions expressed by authors contributing to this journal do not necessarily reflect the opinions of the U.S. Department of Health and Human Services, the Public Health Service, the Centers for Disease Control and Prevention, or the authors' affiliated institutions. 
Table 2. Incidence of Cancer, Mortality, and Total Person-Years for Matched P4P and Non-P4P Patients With Type 2 Diabetes, Taiwan

\begin{tabular}{|c|c|c|c|c|c|c|c|c|c|}
\hline \multirow[b]{2}{*}{ Outcome } & \multicolumn{2}{|c|}{$\begin{array}{c}\text { Total No. Person-Years } \\
\text { Studied }\end{array}$} & \multicolumn{3}{|c|}{ Events } & \multicolumn{2}{|c|}{$\begin{array}{l}\text { Incidence Per } 1,000 \\
\text { Person-Years Studied }\end{array}$} & \multicolumn{2}{|c|}{$\mathrm{IRR}^{\mathrm{a}}$} \\
\hline & P4P & Non-P4P & P4P, N (\%) & $\begin{array}{c}\text { Non-P4P, N } \\
(\%)\end{array}$ & $P$ Value & P4P & Non-P4P & $\begin{array}{l}\text { IRR ( }(95 \% \\
\mathrm{Cl})\end{array}$ & $P$ Value \\
\hline No. & 9,329 & 9,329 & 9,329 & 9,329 & $\mathrm{NA}$ & & & & NA \\
\hline \multicolumn{10}{|l|}{ Cancer incidence } \\
\hline Overall & 59,564 & 56,790 & $800(8.6)$ & $826(8.9)$ & .50 & 13.43 & 14.54 & $\begin{array}{r}0.92 \\
(0.84-1.02)\end{array}$ & .11 \\
\hline Breast & 61,144 & 58,203 & $54(1.1)$ & $62(1.3)$ & .44 & 0.88 & 1.07 & $\begin{array}{r}0.83 \\
(0.56-1.21)\end{array}$ & .32 \\
\hline Colorectal & 61,050 & 58,148 & $112(1.2)$ & $113(1.2)$ & .95 & 1.83 & 1.94 & $\begin{array}{r}0.94 \\
(0.72-1.24) \\
\end{array}$ & .67 \\
\hline Oral & 61,237 & 58,302 & $34(0.4)$ & $35(0.4)$ & .90 & 0.56 & 0.60 & $\begin{array}{r}0.93 \\
(0.56-1.53)\end{array}$ & .75 \\
\hline Liver & 61,059 & 58,124 & $157(1.7)$ & $191(2.1)$ & .07 & 2.57 & 3.29 & $\begin{array}{r}0.78 \\
(0.63-0.97) \\
\end{array}$ & .02 \\
\hline Lung & 61,216 & 58,266 & $76(0.8)$ & $88(0.9)$ & .35 & 1.24 & 1.51 & $\begin{array}{r}0.82 \\
(0.60-1.13) \\
\end{array}$ & .21 \\
\hline Cervical & 61,231 & 58,307 & $29(0.3)$ & $28(0.3)$ & .90 & 0.47 & 0.48 & $\begin{array}{r}0.99 \\
(0.57-1.72) \\
\end{array}$ & .96 \\
\hline Prostate & 61,227 & 58,298 & $35(0.4)$ & $34(0.4)$ & .90 & 0.57 & 0.58 & $\begin{array}{r}0.98 \\
(0.59-1.62) \\
\end{array}$ & .93 \\
\hline Stomach & 61,254 & 58,323 & $44(0.5)$ & $43(0.5)$ & .91 & 0.72 & 0.74 & $\begin{array}{r}0.97 \\
(0.63-1.52)\end{array}$ & .90 \\
\hline Bladder & 61,230 & 58,317 & $29(0.3)$ & $35(0.4)$ & .45 & 0.47 & 0.60 & $\begin{array}{r}0.79 \\
(0.47-1.33)\end{array}$ & .35 \\
\hline \multicolumn{10}{|l|}{ Mortality } \\
\hline All-cause mortality & 61,324 & 58,389 & $1,258(13.5)$ & $2,099(22.5)$ & $<.001$ & 20.51 & 35.95 & $\begin{array}{r}0.57 \\
(0.53-0.61)\end{array}$ & $<.001$ \\
\hline Cancer-specific mortality & 61,324 & 58,389 & $283(3.0)$ & $347(3.7)$ & .010 & 4.61 & 5.94 & $\begin{array}{r}0.78 \\
(0.66-0.91)\end{array}$ & .002 \\
\hline Diabetes-related mortality & 61,324 & 58,389 & $541(5.8)$ & $988(10.6)$ & $<.001$ & 8.82 & 16.92 & $\begin{array}{r}0.52 \\
(0.47-0.58)\end{array}$ & $<.001$ \\
\hline
\end{tabular}

Abbreviations: IRR, incidence rate ratio; NA, not applicable; P4P, pay-for-performance program.

${ }^{\mathrm{a}}$ The non-P4P group is the reference group.

The opinions expressed by authors contributing to this journal do not necessarily reflect the opinions of the U.S. Department of Health and Human Services, the Public Health Service, the Centers for Disease Control and Prevention, or the authors' affiliated institutions. 
Table 3. Adjusted Subdistribution Hazard Ratios (aSHRs) for the Effects of a P4P Program and Antidiabetes Medications on the Risks of Cancer Incidence, Taiwan ${ }^{\text {a }}$

\begin{tabular}{|c|c|c|c|c|c|c|c|c|c|c|}
\hline \multirow[b]{3}{*}{ Cancer } & \multirow{2}{*}{\multicolumn{2}{|c|}{ Program Effects, $\mathrm{P} 4 \mathrm{P}^{\mathrm{C}}$}} & \multicolumn{8}{|c|}{ Antidiabetes Medication Effects ${ }^{b}$} \\
\hline & & & \multicolumn{2}{|c|}{ Metformin } & \multicolumn{2}{|l|}{ SUs } & \multicolumn{2}{|l|}{ TZDs } & \multicolumn{2}{|l|}{ AGIs } \\
\hline & aSHR (95\% Cl) & $P$ Value & $\operatorname{aSHR}(95 \% \mathrm{Cl})$ & $P$ Value & $\operatorname{aSHR}(95 \% \mathrm{Cl})$ & $P$ Value & $\operatorname{aSHR}(95 \% \mathrm{Cl})$ & $P$ Value & $\operatorname{aSHR}(95 \% \mathrm{Cl})$ & $P$ Value \\
\hline Overall & $\begin{array}{r}1.04 \\
(0.94-1.15) \\
\end{array}$ & .42 & $\begin{array}{r}0.58 \\
(0.50-0.67) \\
\end{array}$ & $<.001$ & $\begin{array}{r}1.05 \\
(0.90-1.23) \\
\end{array}$ & .53 & $\begin{array}{r}0.78 \\
(0.70-0.86) \\
\end{array}$ & $<.001$ & $\begin{array}{r}0.62 \\
(0.55-0.69) \\
\end{array}$ & $<.001$ \\
\hline Breast & $\begin{array}{r}0.93 \\
(0.64-1.35) \\
\end{array}$ & .71 & $\begin{array}{r}0.81 \\
(0.46-1.40) \\
\end{array}$ & .44 & $\begin{array}{r}0.67 \\
(0.40-1.13) \\
\end{array}$ & .13 & $\begin{array}{r}0.76 \\
(0.50-1.14) \\
\end{array}$ & .18 & $\begin{array}{r}0.60 \\
(0.40-0.91) \\
\end{array}$ & .02 \\
\hline Colorectal & $\begin{array}{r}1.09 \\
(0.83-1.42) \\
\end{array}$ & .53 & $\begin{array}{r}0.52 \\
(0.36-0.74) \\
\end{array}$ & $<.001$ & $\begin{array}{r}1.81 \\
(1.12-2.93) \\
\end{array}$ & .02 & $\begin{array}{r}0.58 \\
(0.43-0.79) \\
\end{array}$ & .001 & $\begin{array}{r}0.60 \\
(0.44-0.81) \\
\end{array}$ & .001 \\
\hline Oral & $\begin{array}{r}1.08 \\
(0.65-1.78) \\
\end{array}$ & .78 & $\begin{array}{r}0.61 \\
(0.34-1.09) \\
\end{array}$ & .10 & $\begin{array}{r}0.89 \\
(0.47-1.69) \\
\end{array}$ & .72 & $\begin{array}{r}0.83 \\
(0.49-1.41) \\
\end{array}$ & .50 & $\begin{array}{r}0.64 \\
(0.39-1.06) \\
\end{array}$ & .08 \\
\hline Liver & $\begin{array}{r}0.91 \\
(0.73-1.12) \\
\end{array}$ & .37 & $\begin{array}{r}0.48 \\
(0.36-0.63) \\
\end{array}$ & $<.001$ & $\begin{array}{r}1.11 \\
(0.80-1.53) \\
\end{array}$ & .54 & $\begin{array}{r}0.76 \\
(0.60-0.96) \\
\end{array}$ & .02 & $\begin{array}{r}0.47 \\
(0.36-0.61) \\
\end{array}$ & $<.001$ \\
\hline Lung & $\begin{array}{r}0.91 \\
(0.67-1.24) \\
\end{array}$ & .56 & $\begin{array}{r}0.91 \\
(0.56-1.49) \\
\end{array}$ & .72 & $\begin{array}{r}1.57 \\
(0.90-2.77) \\
\end{array}$ & .12 & $\begin{array}{r}0.84 \\
(0.60-1.18) \\
\end{array}$ & .31 & $\begin{array}{r}0.60 \\
(0.42-0.86) \\
\end{array}$ & .005 \\
\hline Cervical & $\begin{array}{r}1.15 \\
(0.68-1.97) \\
\end{array}$ & .60 & $\begin{array}{r}0.44 \\
(0.20-0.94) \\
\end{array}$ & .03 & $\begin{array}{r}0.79 \\
(0.34-1.88) \\
\end{array}$ & .60 & $\begin{array}{r}0.75 \\
(0.43-1.31) \\
\end{array}$ & .31 & $\begin{array}{r}0.72 \\
(0.42-1.24) \\
\end{array}$ & .24 \\
\hline Prostate & $\begin{array}{r}1.06 \\
(0.67-1.70) \\
\end{array}$ & .80 & $\begin{array}{r}0.69 \\
(0.37-1.29) \\
\end{array}$ & .24 & $\begin{array}{r}1.34 \\
(0.64-2.80) \\
\end{array}$ & .43 & $\begin{array}{r}0.67 \\
(0.39-1.15) \\
\end{array}$ & .15 & $\begin{array}{r}0.38 \\
(0.20-0.73) \\
\end{array}$ & .004 \\
\hline Stomach & $\begin{array}{r}1.10 \\
(0.72-1.67) \\
\end{array}$ & .66 & $\begin{array}{r}0.59 \\
(0.33-1.06) \\
\end{array}$ & .08 & $\begin{array}{r}1.04 \\
(0.53-2.07) \\
\end{array}$ & .90 & $\begin{array}{r}1.02 \\
(0.66-1.60) \\
\end{array}$ & .92 & $\begin{array}{r}0.78 \\
(0.48-1.25) \\
\end{array}$ & .30 \\
\hline Bladder & $\begin{array}{r}0.82 \\
(0.49-1.36) \\
\end{array}$ & .44 & $\begin{array}{r}0.73 \\
(0.34-1.60) \\
\end{array}$ & .43 & $\begin{array}{r}1.20 \\
(0.49-2.93) \\
\end{array}$ & .69 & $\begin{array}{r}0.75 \\
(0.43-1.29) \\
\end{array}$ & .30 & $\begin{array}{r}0.59 \\
(0.33-1.03) \\
\end{array}$ & .07 \\
\hline
\end{tabular}

Abbreviations: AGls, $\alpha$ glucosidase inhibitors; Cl, confidence interval; P4P, pay-for-performance program; SUs, sulfonylureas; TZDs, thiazolidinediones.

${ }^{a}$ Competing risk regression models were used to analyze the effects of $\mathrm{P} 4 \mathrm{P}$ and drug effects on risks of cancer incidences while controlling for potential confounders: age, sex, highest level of education, rural or urban residence, baseline comorbidity (diabetes complications severity index and chronic illness with complexity), antidiabetes drug use (metformin, SUs, TZDs, AGls), and health care facility characteristics (accreditation level and geographic regions).

${ }^{b}$ Nonusers of the drug are the reference group for each drug.

${ }^{\mathrm{c}}$ The non-P4P group is the reference group.

The opinions expressed by authors contributing to this journal do not necessarily reflect the opinions of the U.S. Department of Health and Human Services, the Public Health Service, the Centers for Disease Control and Prevention, or the authors' affiliated institutions. 